\title{
Radiofrequency in the treatment of fecal incontinence should no longer be recommended
}

\author{
Valérie Bridoux $^{1} \cdot$ Eloïse Papet ${ }^{1} \cdot$ Jean Pinson $^{1} \cdot$ Jean-Jacques Tuech $^{1}$ CD \\ Accepted: 21 January 2021 / Published online: 1 February 2021 \\ (C) The Author(s), under exclusive licence to Springer-Verlag GmbH, DE part of Springer Nature 2021
}

Dear Editor:

We read with interest the article by Vergara-Fernandez et al. [1] which reports the long-term results of radiofrequency in the treatment of fecal incontinence. They show that this procedure did not maintain its efficacy over time. The literature on radiofrequency in anal incontinence is poor with a low number of publications, especially in recent years. These publications all include a very low number of patients, whereas fecal incontinence is a very common pathology. The shortand medium-term results are not good, with no true clinical improvement because most patients remained in the moderate incontinence category [2]. Nunoo-Mensah [3] raised the hypothesis that the SECCA procedure induces a placebo effect or a certain degree of scarring within the anal canal, which may improve continence. The results of this study are informative and confirm that radiofrequency should no longer be recommended in the treatment of anal incontinence, especially since we did not find a prospective randomized trial registered on ClinicalTrials.gov (https://www.clinicaltrials.gov/).
Jean-Jacques Tuech

jean-jacques.tuech@chu-rouen.fr

1 Department of Digestive Surgery, Hôpital Charles Nicolle, Rouen University Hospital, 1 rue de Germont, F-76031 Rouen

Cedex, France

\section{References}

1. Vergara-Fernandez O, Arciniega-Hernández JA, Trejo-Avila M (2020) Long-term outcomes of radiofrequency treatment for fecal incontinence: are the results maintainable? Int J Color Dis 35:173176

2. Lefebure B, Tuech JJ, Bridoux V, Gallas S, Leroi AM, Denis P, Michot F (2008) Temperature-controlled radio frequency energy delivery (Secca procedure) for the treatment of fecal incontinence: results of a prospective study. Int J Color Dis 23:993-997

3. Nunoo-Mensah JW (2005) Secca procedure for the treatment of fecal incontinence. Dis Colon Rectum 48:175-175; author reply 176

Publisher's note Springer Nature remains neutral with regard to jurisdictional claims in published maps and institutional affiliations. 